УДК 616.89-008.441.44:616-053.71

Для цитирования: Шереметьева И.И., Ведяшкин В.Н. Суицидальное поведение у современных подростков (клиникосоциальный патоморфоз). Сибирский вестник психиатрии и наркологии. 2018; 1 (98): 68-74. https://doi.org/10.26617/18103111-2018-1(98)-68-74

\title{
Суицидальное поведение у современных подростков (клинико-социальный патоморфоз)
}

\author{
Шереметьева И. И. ${ }^{1}$, Ведяшкин В.Н. ${ }^{2}$ \\ ${ }^{1}$ Алтайский государственный медицинский университет \\ Россия, 656056, Барнаул, ул. Луговая, д. 19 \\ ${ }^{2}$ Алтайский краевой психоневрологический диспансер для детей \\ Россия, 656045, Барнаул, ул. Змеиногорский тракт, д. 69
}

\section{PEЗЮME}

Цель - изучение особенностей клинико-социального патоморфоза суицидального поведения у подростков. Материалы и методы. Дизайн исследования: сравнение групп подростков 15-17 лет, получавших амбулаторную и стационарную помощь по поводу отклоняющегося поведения. Среди подростков, получающих амбулаторную и стационарную помощь, сформировано по две группы. Амбулаторная помощь: 1) первая группа - 152 подростка, обследованы в амбулаторном отделении Алтайского краевого психоневрологического диспансера для детей; 2) вторая группа - 147 историй болезни подростков 1970-1979 годов рождения, наблюдавшихся у психиатра амбулаторно. Стационарная помощь: 1) первая группа - 117 подростков, пролеченных в Алтайском краевом наркологическом диспансере; 2) вторая группа - 152 истории пациентов Алтайского краевого наркологического диспансера. Результаты. Социальный портрет современного подростка с отклоняющимся поведением претерпел изменения в сторону проживания в менее благоустроенных условиях, воспитания в семьях с нарушенной структурой или многодетных семьях, с более высокой вовлеченностью в образовательный процесс, с низкой профессионально-трудовой занятостью родителей по сравнению с предыдущим поколением подростков. Средний возраст начала проявления суицидальных угроз и первой суицидальной попытки более ранний у современных подростков. Контингент современных подростков наркологического стационара характеризуется более частым совершением суицидальных попыток, предъявлением суицидальных угроз демонстративного и протестного характера, шантажом суицидом по сравнению с подростками предыдущего поколения.

Ключевые слова: подросток, суицид, патоморфоз, отклоняющееся поведение, структура.

\section{ВВЕДЕНИЕ}

Важность изучения психических расстройств у подростков актуально не одно десятилетие, особенно когда обнаруживается тенденция к росту проявлений и формированию новых форм отклоняющегося поведения в подростковом возрасте [10, 12, 16, 17, 29]. Наиболее уязвимыми к развитию аутодеструктивного поведения оказываются подростки. В настоящее время они составляют наибольшую по численности возрастную группу на планете - 1,8 биллиона человек, т.е. четверть населения планеты. В подростковом возрасте резко возрастает опасность утраты физического здоровья в результате травм разного генеза, приема ПАВ, агрессии и суицидов в совокупности это составляет первую причину смертности среди подростков. Именно в этом возрасте чаще всего манифестируют наиболее распространенные психические расстройства, которые сами по себе повышают риск суицидального поведения [25]. Среди различных форм поведенческих нарушений суицидальное поведение занимает лидирующую позицию по уровню угрозы жизни подрастающему поколению [7, 26, 27, 28, 29]. В своих исследованиях мы неоднократно подтверждали высокую актуальность суицидального поведения среди несовершеннолетних $[4,5,6,7,9]$. Происходящая определенная трансформация доминирующих «идеологических» течений в молодежной субкультуре влияет на общие тенденции поведения несовершеннолетних [3, 18, 19].
Особого внимания заслуживает проблема влияния Интернета и иных современных средств коммуникации на подрастающее поколение $[11,22]$. В условиях стремительных социальных перемен и глобальных негативных изменений природной среды (урбанизация, естественные и техногенные региональные экологические катастрофы и др.) эволюция болезней, в том числе и нервно-психических, ускоряется, её темпы возросли в десятки раз [21]. Актуальность изучения трансформации клиники различных психических расстройств не раз озвучивалась многими авторами $[14,20]$. Однако изучению патоморфоза психических расстройств уделяется недостаточное внимание [1, 15].

Цель исследования - изучить особенности клинико-социального патоморфоза суицидального поведения у подростков.

\section{МАТЕРИАЛЫ И МЕТОДЫ}

Для достижения цели работы использован оригинальный четырехклеточный дизайн исследования: сравнивались группы подростков, получавших амбулаторную и стационарную помощь по поводу отклоняющегося поведения.

Для исследования патоморфоза суицидального поведения у подростков 15-17 лет, получавших амбулаторную помощь у психиатра, проведено клиническое обследование с последующим сравнением двух групп подростков с поведенческими нарушениями. Первая группа (I) - 152 подростка, обследо- 
ваны в амбулаторном отделении Алтайского краевого психоневрологического диспансера для детей. Вторая группа (II) набиралась из архивных данных, проанализированы 147 историй болезни пациентов, родившихся в период с 1970 по 1979 г. и наблюдавшихся в подростковом возрасте амбулаторно у психиатра по поводу расстройства поведения. Данный временной период выбран с целью учета дисперсии возраста, так как средний интервал между поколениями составляет 25 лет.

При исследовании патоморфоза отклоняющегося поведения у подростков 15-17 лет, получающих стационарную помощь, так же сформировано две группы. Первая группа (III) - 117 больных с отклоняющимся поведением (73 юноши и 44 девушки), находившихся на стационарном лечении в Алтайском краевом наркологическом диспансере. Вторая группа (IV) - архивные данные Алтайского краевого наркологического диспансера, 152 истории болезни и прилагаемые к ним сопроводительные документы (характеристики, ходатайства, копии административных и уголовных постановлений), в том числе 120 юношей и 32 девушки, проходивших стационарное лечение в Алтайском краевом наркологическом диспансере с 01.01.2001 г. по 30.06.2002 г.

Ряд авторов отмечает, что в последнее время происходит перераспределение зависимого употребления, характеризующееся приемом более «легких» наркотиков, появлением на рынке сбыта синтетических курительных смесей, сокращением распространенности наркотиков опийного ряда, особенно в молодежной среде 16-20 лет [2, 8, 24].

Учитывая эти данные, нам представлялось интересным провести сравнительное исследование между данными группами с учетом произошедших изменений на рынке употребляемых наркотических веществ. Поэтому временной интервал между поколениями подростков, пролеченных в наркологическом стационаре, был выбран в 10-12 лет.

Согласно мнению Г.В. Талалаевой [23], наркомания является биосоциальным циклом, совпадающим с мировыми войнами, техническими и технологическими революциями, социальными трансформациями в обществе. Циклы глобальных эпидемий равны примерно 25-30 годам. На уровне регионов и федеральных округов ритмы наркомании ускоряются до циклов с продолжительностью от 10 до 14 лет. На уровне более мелких географических образований (отдельных населенных пунктов и муниципальных образований) циклы наркомании ещё более ускоряются до периода, равного от 3 до 5 и 7 лет $[13,23]$. Несомненно, данная закономерность опосредованно влияет на трансформацию отклоняющегося поведения в целом и суицидальное поведение в частности.

Критериями отбора пациентов в группы служили клинические проявления, соответствующие рубрикам МКБ-10: «несоциализированное расстройство поведения» (F91.1) и «социализированное расстройство поведения» (F91.2).
Из исследования заведомо исключались лица, страдающие процессуальными эндогенными, текущими экзогенно-органическими заболеваниями, с расстройствами зрелой личности и поведения у взрослых, умственно отсталые подростки.

Для исследования применялись клиникопсихопатологический метод и метод статистической обработки материала.

\section{РЕЗУЛЬТАТЫ И ОБСУЖДЕНИЕ}

Результаты исследования амбулаторного контингента

Анализ результатов исследования показал, что социальный портрет современного подростка, получающего амбулаторную помощь у психиатра, претерпел некоторые изменения.

Современные подростки (группа I) с достоверно более высокой частотой (p<0,001) вовлечены в образовательный процесс по сравнению с подростками предыдущего поколения (группа II). Не обучались в учебных заведениях $2 \%$ подростков I группы и 29,3\% подростков II группы. Это можно объяснить тем, что с 1992 г. действует закон об обязательном получении среднего образования несовершеннолетними, а большинство пациентов II группы на момент вступления закона в силу являлись совершеннолетними.

В среднеобразовательной школе (СОШ) на момент обращения к психиатру обучалось 58,6\% подростков I группы, подростки II группы с достоверно значимой более низкой частотой $(\mathrm{p}<0,001)$ обучались в СОШ (13,6\%). Среднее специальное образование (профессиональные училища, лицеи, техникумы) на момент обследования получали $34,2 \%$ подростков I группы. Подростки II группы с достоверно более высокой частотой $(\mathrm{p}<0,01)$ получали среднее специальное образование $(49,7 \%)$. Выявлен небольшой процент подростков I и II групп, обучавшихся в высшем учебном заведении, что не имело статистически значимых различий (р>0,05) (табл. 1).

Т а б л и ц а 1 Распределение амбулаторно пролеченных подростков по участию в образовательном процессе

\begin{tabular}{|l|c|c|c|c|c|}
\hline \multirow{2}{*}{ Образование } & \multicolumn{2}{|c|}{ І группа } & \multicolumn{2}{|c|}{ I группа } & \multirow{2}{*}{$\mathrm{p}$} \\
\cline { 2 - 6 } & Абс. & $\%$ & Абс. & $\%$ & \\
\hline Не организован & 3 & 2 & 43 & 29,3 & $\mathrm{p}<0,001$ \\
\hline $\begin{array}{l}\text { Среднеобразовательная } \\
\text { школа }\end{array}$ & 89 & 58,6 & 20 & 13,6 & $\mathrm{p}<0,001$ \\
\hline Среднее специальное & 52 & 34,2 & 73 & 49,7 & $\mathrm{p}<0,01$ \\
\hline Высшее & 8 & 5,3 & 11 & 7,5 & $\mathrm{p}>0,05$ \\
\hline
\end{tabular}

Жилищно-бытовые условия проживания подростков различных поколений, получавших амбулаторную психиатрическую помощь по поводу отклоняющегося поведения, имели ряд особенностей. Так, подростки I группы с достоверной значимостью реже $(\mathrm{p}<0,001)$ проживают в благоустроенных квартирах $(46,7 \%)$ по сравнению с подростками предыдущих поколений $(70,7 \%)$. При этом они с достоверно более высокой частотой $(\mathrm{p}<0,001)$ проживают в частных домах $(30,9 \%)$, чем подростки II группы $(11,6 \%)$. По проживанию в общежитиях и детских 
домах статистически достоверно значимых различий не отмечается (p>0,05) (табл. 2).

Т а б ли ц а 2

Распределение амбулаторно пролеченных подростков по жилищно-бытовым условиям проживания

\begin{tabular}{|l|c|c|c|c|c|}
\hline \multirow{2}{*}{ Место проживания } & \multicolumn{2}{|c|}{ I группа } & \multicolumn{2}{|c|}{ II группа } & \multirow{2}{*}{ p } \\
\cline { 2 - 6 } & Абс. & $\%$ & Абс. & $\%$ & \\
\hline Квартира & 71 & 46,7 & 104 & 70,7 & $\mathrm{p}<0,001$ \\
\hline Общежитие & 11 & 7,2 & 7 & 4,8 & $\mathrm{p}>0,05$ \\
\hline Дом & 47 & 30,9 & 17 & 11,6 & $\mathrm{p}<0,001$ \\
\hline Детский дом & 23 & 15,1 & 19 & 12,9 & $\mathrm{p}>0,05$ \\
\hline
\end{tabular}

Как показано в таблице 3, в обеих группах большинство подростков воспитывались либо в полной семье, либо одной матерью. Статистически достоверные различия $(\mathrm{p}<0,001)$ выявлены только в случае многодетных семей, в I группе их насчитывалось значительно больше $(22,4 \%)$, чем во II группе $(4,8 \%)$.

Т а б л и ц а 3 Распределение амбулаторно пролеченных подростков

\begin{tabular}{|l|c|c|c|c|c|}
\multicolumn{1}{c|}{$\begin{array}{c}\text { Структура } \\
\text { семьи }\end{array}$} & \multicolumn{2}{|c|}{ I группа } & \multicolumn{2}{c|}{ II группа } & \multirow{2}{*}{$\mathrm{p}$} \\
\cline { 2 - 6 } \multicolumn{1}{|c|}{} & Абс. & $\%$ & Абс. & $\%$ & \\
\hline Полная семья & 56 & 36,8 & 64 & 43,5 & $\mathrm{p}>0,05$ \\
\hline Одна мать & 58 & 38,2 & 49 & 33,3 & $\mathrm{p}>0,05$ \\
\hline Один отец & 4 & 2,6 & 7 & 4,8 & $\mathrm{p}>0,05$ \\
\hline Воспитывается опекуном & 11 & 7,2 & 8 & 5,4 & $\mathrm{p}>0,05$ \\
\hline Сирота & 23 & 15,1 & 19 & 12,9 & $\mathrm{p}>0,05$ \\
\hline Многодетная семья & 34 & 22,4 & 7 & 4,8 & $\mathrm{p}<0,001$ \\
\hline
\end{tabular}

Профессиональная занятость родителей оценивалась без учета подростков, имеющих статус сироты. Матери работали у 96 (63,2\%) подростков, а отцы - у 81 (53,3\%) подростка. Во II группе из архивных материалов вышеизложенные данные собрать не удалось.

В отношении проявления суицидального поведения получены были следующие результаты. Суицидальные угрозы предъявляли 83 (54,6\%) подростка I группы и 74 (50,3\%) подростка II группы, что не имело статистически достоверных различий между группами (p>0,05). Средний возраст, с которого начинали предъявлять суицидальные угрозы под-

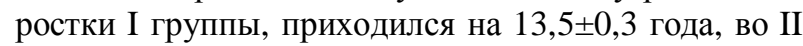
группе с достоверной значимостью $(\mathrm{p}<0,001)$ суицидальные угрозы встречались практически на 2 года позже - 15,6 $\pm 0,2$ года.

Т а б л и ц а 4 Распределение амбулаторно пролеченных подростков по предъявляемым суицидальным угрозам

\begin{tabular}{|l|c|c|c|c|c|}
\hline \multirow{2}{*}{$\begin{array}{c}\text { Суицидальные } \\
\text { угрозы }\end{array}$} & \multicolumn{2}{|c|}{ І группа } & \multicolumn{2}{|c|}{ IІ группа } & \multirow{2}{*}{ р } \\
\cline { 2 - 5 } Демс. & $\%$ & Абс. & $\%$ & \\
\hline Шанстративные & 50 & 60,2 & 40 & 54,1 & $\mathrm{p}>0,05$ \\
\hline Протажные & 18 & 21,7 & 24 & 32,4 & $\mathrm{p}>0,05$ \\
\hline
\end{tabular}

В таблице 4 наглядно представлен характер суицидальных угроз. С целью привлечь к себе внимание демонстративно угрожали покончить жизнь самоубийством 50 (60,2\%) современных подростков против 40 (54,1\%) подростков предыдущего поколения. С целью добиться желаемого шантажировали суицидом 18 (21,7\%) подростков I группы и 24
$(32,4 \%)$ подростка II группы. В знак протеста или несогласия с предъявляемыми требованиями угрожали суицидом 26 (31,3\%) современных подростков и 24 (32,4\%) подростка предыдущего поколения. Протестные суицидальные угрозы в большинстве случаев предъявляли сироты, находящиеся в интернированных образовательных учреждениях. Статистически достоверные различия по характеру суицидальных угроз между группами отсутствовали $(\mathrm{p}>0,05)$.

Т а б ли ц а 5 Распределение амбулаторно пролеченных подростков по суицидальной активности

\begin{tabular}{|c|c|c|c|c|c|}
\hline \multirow{2}{*}{$\begin{array}{c}\text { Суицидальные } \\
\text { угрозы }\end{array}$} & \multicolumn{2}{|c|}{ I группа } & \multicolumn{2}{|c|}{ II группа } & \multirow[t]{2}{*}{$\mathrm{P}$} \\
\hline & Абс. & $\%$ & Абс. & $\%$ & \\
\hline Кол-во суицидентов & 45 & 29,6 & 59 & 40,1 & $p>0,05$ \\
\hline $\begin{array}{l}\text { Из них с повторными } \\
\text { попытками }\end{array}$ & 17 & 37,8 & 34 & 57,6 & $p>0,05$ \\
\hline Среднее кол-во попыток & \multicolumn{2}{|c|}{$2,4 \pm 1$} & \multicolumn{2}{|c|}{$2,3 \pm 0,4$} & $p>0,05$ \\
\hline $\begin{array}{l}\text { Средний возраст первой } \\
\text { попытки }\end{array}$ & \multicolumn{2}{|c|}{$14,5 \pm 0,4$} & \multicolumn{2}{|c|}{$16,2 \pm 0,3$} & $\mathrm{p}<0,001$ \\
\hline
\end{tabular}

В соответствии с таблицей 5 суицидальные попытки в I группе совершали 45 (29,6\%) подростков, во II группе - $59(40,1 \%)$ подростков. Из них неоднократные суицидальные попытки в I группе совершали 17 (37,8\%) человек, во II группе - 34 $(57,6 \%)$ несовершеннолетних. Среднее количество

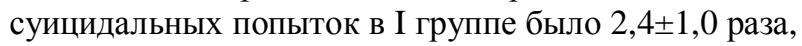
во II группе - 2,3 $\pm 0,4$ раза. По всем трем перечисленным выше показателям суицидальной активности между группами не обнаружено статистически достоверных различий $(\mathrm{p}>0,05)$. Средний возраст первой суицидальной попытки в I группе был стати-

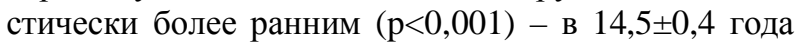
по сравнению со II группой, где средний возраст первой суицидальной попытки приходился на $16,2 \pm 0,3$ года.

Результаты исследования стационарного контингента

Что касается подростков, получавших помощь в стационаре наркологического профиля, то необходимо отметить, что большинство современных подростков проходили лечение в наркологическом стационаре по поводу злоупотребления алкоголем или каннабиноидами, тогда как в 2001-2002 гг. подростки получали лечение по поводу острого абстинентного синдрома при употреблении опиатов. Анализ результатов выглядел следующим образом.

Как показано в таблице 6, современные подростки (группа III) с достоверно значимой более высокой частотой $(\mathrm{p}<0,001)$ вовлечены в образовательный процесс, нежели подростки, получавшие лечение в наркологическом стационаре в 2001-2002 гг. (группа IV). В III группе на момент лечения в среднеобразовательной школе обучались $34,2 \%$ подростков, в IV группе - 12,5\%. Среднее специальное образование в III группе получали $34,2 \%$ обследованных подростков, в IV группе - 12,5\%. На момент обследования не обучались ни в одном образовательном учреждении в III группе $4,3 \%$ опрошенных, в IV группе - более половины $(56,6 \%)$. 
Т а б л и ц а 6

Распределение стационарно пролеченных подростков по участию в образовательном процессе

\begin{tabular}{|l|c|c|c|c|c|}
\hline \multirow{2}{*}{ Образование } & \multicolumn{2}{|c|}{ III группа } & \multicolumn{2}{c|}{ IV группа } & \multirow{2}{*}{$\mathrm{p}$} \\
\cline { 2 - 5 } & Абс. & $\%$ & Абс. & $\%$ & \\
\hline Не организован & 5 & 4,3 & 86 & 56,6 & $\mathrm{p}<0,001$ \\
\hline $\begin{array}{l}\text { Среднеобразовательная } \\
\text { школа }\end{array}$ & 40 & 34,2 & 19 & 12,5 & $\mathrm{p}<0,001$ \\
\hline Среднее специальное & 72 & 61,5 & 47 & 30,9 & $\mathrm{p}<0,001$ \\
\hline
\end{tabular}

Согласно данным таблицы 7, достоверно больше ( $<<0,001)$ подростков предыдущего поколения проживало в благоустроенной квартире $(67,1 \%)$, в то время как достоверно больше $(\mathrm{p}<0,005)$ современных подростков проживало в частном доме $(44,4 \%)$. Достоверно больше $(\mathrm{p}<0,001)$ современных подростков, получавших лечение в наркологическом стационаре, имели статус сироты, $23,1 \%$ проживали в детском доме.

Т а б ли ц а 7

Распределение стационарно пролеченных подростков
по жилищно-бытовым условиям проживания
\begin{tabular}{|l|c|c|c|c|c|}
\hline \multirow{2}{*}{ Место проживания } & III группа & IV группа & \multirow{2}{*}{$\mathrm{p}$} \\
\cline { 2 - 6 } & Aбс. & $\%$ & Aбс. & $\%$ & \\
\hline Квартира & 34 & 29,1 & 102 & 67,1 & $\mathrm{p}<0,001$ \\
\hline Общежитие & 4 & 3,4 & 3 & 2 & $\mathrm{p}>0,05$ \\
\hline Дом & 52 & 44,4 & 42 & 27,6 & $\mathrm{p}<0,005$ \\
\hline Детский дом & 27 & 23,1 & 5 & 3,3 & $\mathrm{p}<0,001$ \\
\hline
\end{tabular}

Представленная в таблице 8 структура семейной системы у подростков изученных групп выглядела следующим образом. В полной семье, где воспитанием занимались оба родителя, воспитывалось достоверно значимое меньшее $(\mathrm{p}<0,05)$ число подростков III группы $(29,1 \%)$ в сравнении с IV группой (40,8\%). В III группе воспитанием подростка в $35 \%$ случаев занималась только мать, в IV группе - незначительно больше $(48,7 \%)$. При этом в III группе воспитанием ребенка отец в одиночку занимался с более высокой частотой $(6,8 \%)$, чем в IV группе, где отец самостоятельно воспитывал только одного подростка. Различия в воспитании одного из родителей являются достоверно значимыми $(\mathrm{p}<0,05)$. В отношении подростков, которые находились под опекой, между обеими группами достоверных различий выявлено не было. Как уже было сказано выше, статус сироты имело достоверно значимое $(\mathrm{p}<0,001)$ большее число подростков III группы $(23,1 \%)$, чем в IV группе $(3,3 \%)$. В III группе достоверно значимое $(\mathrm{p}<0,05)$ более высокое число подростков было из многодетной семьи $(15,4 \%)$, чем в IV группе $(5,9 \%)$.

Т а б л и ц а 8

\begin{tabular}{|c|c|c|c|c|c|}
\hline \multicolumn{6}{|c|}{$\begin{array}{c}\text { Распределение стационарно пролеченных подростков } \\
\text { по структуре семьи }\end{array}$} \\
\hline \multirow{2}{*}{$\begin{array}{l}\text { Структура } \\
\text { семьи }\end{array}$} & \multicolumn{2}{|c|}{ III группа } & \multicolumn{2}{|c|}{ IV группа } & \\
\hline & Абс. & $\%$ & Абс. & $\%$ & \\
\hline семья & 34 & 29,1 & 62 & 40,8 & 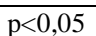 \\
\hline Одн & 41 & U & 7. & 48,7 & \\
\hline Один & 8 & 6 , & & 0,7 & $p<0,05$ \\
\hline Воспитывае & 7 & 6,0 & 10 & 6,5 & $p>0,05$ \\
\hline Сирота & 27 & 23,1 & 5 & 3,3 & $\mathrm{p}<0,001$ \\
\hline Многодетная семья & 18 & 15,4 & 9 & 5,9 & $p<0,05$ \\
\hline
\end{tabular}

Профессиональная занятость родителей оценивалась так же без учета подростков, имеющих статус сироты. В III группе как матери $(61,1 \%)$, так и отцы $(53,3 \%)$ с достоверной значимостью меньше ( $<<0,05)$ работали, чем в IV группе, где трудом было занято $74,1 \%$ матерей и $60,5 \%$ отцов.

Что касается отклоняющегося поведения суицидального характера, то были выявлены следующие результаты. Суицидальные угрозы предъявляли 70 $(59,8 \%)$ подростков III группы, т. е. с достоверно более высокой частотой $(\mathrm{p}<0,05)$ по сравнению с подростками IV группы, где суицидальные угрозы предъявляли 67 (44,1\%) подростков. Средний возраст первых угроз суицидального характера в III

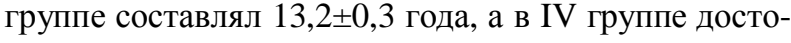

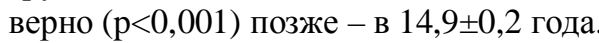

Т а б ли ц а 9

Распределение стационарно пролеченных подростков по предъявляемым суицидальным угрозам

\begin{tabular}{|l|c|c|c|c|c|}
\hline \multirow{2}{*}{$\begin{array}{c}\text { Суицидальные } \\
\text { угрозы }\end{array}$} & \multicolumn{2}{|c|}{ III группа } & \multicolumn{2}{c|}{ IV группа } & \multirow{2}{*}{$\mathrm{p}$} \\
\cline { 2 - 6 } & Aбс. & $\%$ & Абс. & $\%$ & \\
\hline Демонстративные & 36 & 51,4 & 20 & 29,9 & $\mathrm{p}<0,05$ \\
\hline Шантажные & 19 & 27,1 & 47 & 70,1 & $\mathrm{p}<0,001$ \\
\hline Протестные & 22 & 31,4 & 8 & 11,9 & $\mathrm{p}<0,05$ \\
\hline
\end{tabular}

Как наглядно представлено в таблице 9, суицидальные угрозы демонстративного характера, с целью привлечь к себе внимание с достоверно значимой более высокой частотой $(\mathrm{p}<0,05)$ предъявляли подростки III группы (36 - 51,4\%) по сравнению c IV группой $(20$ - 29,9\%). Суицидальные угрозы шантажного характера, с целью добиться желаемого, любым способом настоять на своём с достоверной значимостью чаще $(\mathrm{p}<0,01)$ встречались у подростков IV группы $(47-70,1 \%)$ по сравнению с III группой $(19-27,1 \%)$. Протестные суицидальные угрозы с целью неповиновения, активного отказа подчиниться в III группе предъявлялись с достоверно значимой $(\mathrm{p}<0,05)$ более высокой частотой $(22-$ $31,4 \%$ ) по сравнению с IV группой, где протестные угрозы предъявляли 8 (11,9\%) подростков.

Т а б л и ц а 10

Распределение стационарно пролеченных подростков по суицидальной активности

\begin{tabular}{|l|c|c|c|c|c|}
\hline \multicolumn{1}{|c|}{$\begin{array}{l}\text { Суицидальные } \\
\text { угрозы }\end{array}$} & \multicolumn{2}{|c|}{ III группа } & \multicolumn{2}{|c|}{ IV группа } & \multirow{2}{*}{ Р } \\
\cline { 2 - 6 } & Абс. & $\%$ & Абс. & $\%$ & \\
\hline Кол-во суицидентов & 38 & 32,5 & 30 & 19,7 & $\mathrm{p}<0,05$ \\
\hline $\begin{array}{l}\text { Из них с повторными } \\
\text { попытками }\end{array}$ & 16 & 42,1 & 13 & 43,3 & $\mathrm{p}>0,05$ \\
\hline Среднее кол-во попыток & \multicolumn{2}{|c|}{$1,7 \pm 0,4$} & $1,6 \pm 0,3$ & $\mathrm{p}>0,05$ \\
\hline $\begin{array}{l}\text { Средний возраст первой } \\
\text { попытки }\end{array}$ & \multicolumn{2}{|c|}{$14 \pm 0,4$} & $15,1 \pm 0,4$ & $\mathrm{p}<0,001$ \\
\hline
\end{tabular}

Согласно данным таблицы 10, в III группе достоверно значимое $(\mathrm{p}<0,05)$ более высокое число подростков совершали суицидальные попытки (38 $32,5 \%$ ) по сравнению с подростками IV группы, где суицидальные попытки совершали 30 (19,7\%) человек. Из них повторные суицидальные попытки в III группе совершали 16 (42,1\%) подростков, в IV группе - $13(43,3 \%)$ подростков, что не имело статистически достоверных различий $(\mathrm{p}>0,05)$. Среднее количество суицидальных попыток в III группе со- 
ставляло $1,7 \pm 0,4$, в IV группе - 1,6 $\pm 0,3$ попытки, что не имело достоверных различий $(\mathrm{p}>0,05)$. Средний возраст первой суицидальной попытки у подростков

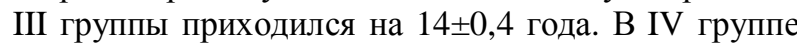
подростков средний возраст первой попытки суицида по сравнению с III группой с достоверной значимостью $(\mathrm{p}<0,001)$ был более поздним $(15,1 \pm 0,4$ года).

\section{ВЫВОДЫ}

Социальный портрет современного подростка с отклоняющимся поведением претерпел изменения в сторону проживания в менее благоустроенных условиях, в семьях с нарушенной структурой, в многодетных семьях, где менее высокая трудовая занятость родителей, но более высокая вовлеченность самих подростков в образовательный процесс по сравнению с предыдущим поколением.

Средний возраст начала проявления суицидальных угроз и первой суицидальной попытки более ранний у современных подростков.

Современные подростки - пациенты наркологического стационара чаще совершали суицидальные попытки, чаще предъявляли суицидальные угрозы демонстративного и протестного характера, чаще шантажировали суицидом по сравнению с подростками предыдущего поколения, что можно объяснить произошедшей сменой в сторону употребления более «легких» наркотиков.

\section{КОНФЛИКТ ИНТЕРЕСОВ}

Авторы заявляют об отсутствии конфликта интересов в связи с публикацией данной статьи.

\section{ИСТОЧНИК ФИНАНСИРОВАНИЯ}

Авторы заявляют об отсутствии финансирования при проведении исследования.

\section{СООТВЕТСТВИЕ ПРИНЦИПАМ ЭТИКИ}

Работа соответствует этическим стандартам Хельсинской декларации ВМА (протокол заседания этического комитета Алтайского государственного медицинского университета № 14 от 29.11.2010).

\section{ЛИТЕРАТУРА}

1. Абабков В. А. Неврозы. СПб.: Изд-во Диля, 2002: 160.

2. Аболонин А.Ф., Трефилова Л.Л. Динамика и структура употребления ПАВ среди подростков Томской области. Актуальные вопросы психиатрии и наркологии: материалы 15 й научной отчетной сессии НИИ психического здоровья СО РАМН / под ред. В.Я. Семке. Томск: Иван Федоров, 2011: 204-205.

3. Бохан Н.А. Наркоситуация в среде высокообразованной молодежи: новые вызовы старых проблем. Актуальные вопросы психического здоровья, перспективы развития психиатрической службы / сост. В.А. Макашева, Д. Суворова. Новосибирск: Сибмедиздат, 2013: 17-22.

4. Ведяшкин В.Н. Вопросы реабилитации суицидального поведения у детей и подростков Алтайского края. Нарушения поведения у детей, современные подходы к диагностике и терапии: сборник тезисов докладов межрегиональной научно-практической конференции. Барнаул: Изд-во «Арбат», 2015: 10-13.

5. Ведяшкин В.Н., Шереметьева И.И. Изменения клиникосоциальных характеристик суицидального поведения подростков-пациентов наркологического стационара за 10 лет. XVI съезд психиатров России. Всероссийская научнопрактическая конференция с международным участием «Психиатрия на этапах реформ: проблемы и перспективы
[Электронный ресурс] / под общ. ред. Н.Г. Незнанова. СПб.: Альта Астра, 2015: 887.

6. Ведяшкин В.Н., Шереметьева И.И. Организация профилактики и анализа суицидального поведения у детей и подростков Алтайского края. Детская психиатрия: современные вопросы диагностики, терапии, профилактики и реабилитации: сб. материалов Всероссийской научно-практической конференции с международным участием / под ред. Н.Г. Незнанова, И.В. Макарова. СПб., 2014: 23-24.

7. Ведяшкин В.Н., Шереметьева И.И. Организация суицидологической помощи подросткам Алтайского края. Сибирский вестник психиатрии и наркологии. 2016; 3 (92): 75-80.

8. Ведяшкин В.Н., Шереметьева И.И. Особенности патоморфоза аддикций у подростков. Уральский медицинский журнал. 2014; 01 (115): 122-126.

9. Ведяшкин В.Н., Шереметьева И.И. Патоморфоз суицидального поведения у подростков. Вестник психиатрии и психологии Чуватии. 2015; 11 (3): 61-68.

10. Вострокнутов Н.В., Шалимов В.Ф., Новикова Г.Р. Стационарзамещающая технология социально-психиатрической помощи детям: методические рекомендации. М., 2010: 20.

11. Демдоуми Н.Ю., Денисов Ю.П. Распространение «суицидального контента» в киберпространстве русскоязычного интернета как проблема мультидисциплинарных исследований. Суицидология. 2014; 5 (15): 47-54.

12. Драгунова Т.В. Некоторые общие вопросы изучения личности подростка. Вопросы изучения детей с отклонениями в поведении: материалы конференции. М., 1968: 7-19.

13. Какорина Е.П., Казаковцев Б.А., Голланд В.Д. Смертность от психических расстройств и смертность при психических расстройствах. Психическое здоровье. 2015; 3: 22-27.

14. Караваева Т.А. Особенности изменения структуры заболеваемости и клинической картины невротических и неврозоподобных расстройств за последние три десятилетия. Актуальные проблемы психосоматики в общемедицинской практике: 10-я научно-практическая конференция / под общ. ред. В.И. Мазурова. СПб., 2010: 75-79.

15. Караваева Т.А. Патоморфоз невротических расстройств, их психотерапия и её правовое регулирование: автореф. дис. ... д.м.н. СПб., 2011: 57c.

16. Кузенкова Н.Н. Диагностика и военно-врачебная экспертиза психических расстройств у подростков: методические рекомендации. Барнаул, 2003: 38.

17. Макушкин Е.В. Клинико-эпидемиологические характеристики психических расстройств у детей и подростков в РФ. Актуальные вопросы психического здоровья, перспективы развития психиатрической службы / сост. В.А. Макашева, Д. Суворова. Новосибирск: Сибмедиздат, 2013: 9-12.

18. Можгинский Ю.Б. Психические болезни у подростков: психопатология, лечение : клиническое руководство. М.: Триадафарм, 2003: 215.

19. На пути к преступлению: девиантное поведение подростков и риски взросления в современной России (опыт социологического анализа) / под науч. ред. М.Е. Поздняковой, Т.А. Хагурова. М.; Краснодар: Институт социологии, 2012: 344.

20. Патоморфоз психических заболеваний в судебнопсихиатрической клинике: сб. науч. тр. / под ред. Г.В. Морозова. М., 1985: 168.

21. Патоморфоз психологических характеристик больных с невротическими расстройствами за последние 30 лет / Б.Д. Карвасарский, Е.Б. Мизинова, Е.А. Колотильщикова и др. СПб., 2011: 28.

22. Солдатова Г.В., Рассказова Е.И. Как им помочь? Ребенок в Интернете: запрещать, наблюдать или объяснять? Дети в информационном обществе. 2012; 0: 26-33.

23. Талалаева Г.В. Социальная демография. Учебное пособие. Екатеринбург, 2010: 173.

24. Тетенова Е.Ю. Динамика основных показателей употребления психоактивных веществ у пользователей русскоязычного сегмента Интернета (2008-2011 гг.). Психическое здоровье. 2013; 5: 12-16.

25. Холмогорова А.Б. Предисловие главного редактора. Консультативная психология и психотерапия. 2016; 24 (3): 5-7. 
26. Bertolote J.M.F., Fleischmann A. Suicidal behavior prevention WHO perspectives on research. Am. J. Med. Genet. 2005; 133: 8-12.

27. Brauser D. Insufficient evidence to support universal suicide screening. Medscape medical news. 24.04.2013 URL: http://www.medscape.com/ viewarticle/803068.

28. Canavan N. Almost $20 \%$ of suicidal teens live in home with a gun. Medscape medical news. 08.05.2013 URL: http://www.medscape.com/ viewarticle/803856.
29. Chung R.H. Gender, ethnicity, and acculturation in intergenerational conflict of Asian American college students. Cultur Devers Ethnic Minor Psychol. 2001; 7 (4): 376-386.

Поступила в редакцию 17.09.2017 Утверждена к печати 5.02.2018

Шереметьева Ирина Игоревна, д.м.н., проф., заведующая кафедрой психиатрии, медицинской психологии и неврологии с курсом ДПО. Ведяшкин Виктор Николаевич, к.м.н., заместитель главного врача по лечебной работе.

Шереметьева Ирина Игоревна, sheremeteva-ira@mail.ru

УДК 616.89-008.441.44:616-053.71

For citation: Sheremetyeva I.I., Vedyashkin V.N. Special aspects of clinical and social pathomorphosis of adolescent's suicidal performance. Siberian Herald of Psychiatry and Addiction Psychiatry. 2018; 1 (98): 68-74. https://doi.org/10.26617/1810-31112018-1(98)-68-74

\section{Special aspects of clinical and social pathomorphosis of adolescent's suicidal performance}

\section{Sheremetyeva I.I. ${ }^{1}$, Vedyashkin V.N. ${ }^{2}$}

${ }^{1}$ Altay State Medical University

Lugovaya Street 19, 656056, Barnaul, Russian Federation

${ }^{2}$ Altay Regional Psychoneurological Clinic for Children

Zmeinogorsky Trakt 69, 656045, Barnaul, Russian Federation

\section{ABSTRACT}

Purpose - study of features of clinical-social pathomorphosis of suicidal behaviour in adolescents. Materials and Methods. Design of research: comparison of groups of adolescents aged 15-17 years receiving the out-patient and inpatient care concerning deviant behaviour. Among adolescents receiving the out-patient and inpatient care, two groups were created. The out-patient care: 1) the first group - 152 adolescents, were examined in out-patient unit of the Altay Regional Psychoneurological Clinic for Children; 2) the second group - 147 case records of adolescents of 1970-1979 year of birth), observed at the psychiatrist were outpatients. The inpatients care: 1) the first group - 117 adolescents treated at the Altay Regional Narcological Clinic; 2) the second group - 152 stories of the Altay Regional Narcological Clinic. Results. The social portrait of the modern adolescent with deviant behaviour has undergone changes towards residing in less arranged well conditions, brought up in families with the broken structure or large families, with higher involvement into educational process, with low professional-labour employment of parents in comparison with the previous generation of adolescents. Mean age of the beginning of manifestation of suicide threats and the first suicide attempt is earlier in modern adolescents. The contingent of modern adolescents of a narcological hospital is characterized by more frequent fulfilment of suicide attempts, a presentation of suicide threats of demonstrative and protest character, blackmail by a suicide in comparison with adolescents of the previous generation.

\section{Keywords: adolescent, suicide, pathomorphosis, deviant behavior, structure.}

\section{REFERENCES}

1. Ababkov V.A. Nevrozyi [Neuroses]. SPb.: Izd-vo Dilya, 2002 160 (in Russian).

2. Abolonin A.F., Trefilova L.L. Dinamika i struktura upotrebleniya PAV sredi podrostkov Tomskoy oblasti [Dynamics amd structure of substance use among adolescents of the Tomsk Region]. Aktualnyie voprosyi psihiatrii i narkologii: materialyi 15 -y nauchnoy otchetnoy sessii NII psihicheskogo zdorovya SO RAMN / pod red. V.Ya. Semke. Tomsk: Ivan Fedorov, 2011: 204-205 (in Russian).

3. Bokhan N.A. Narkosituatsiya $\mathrm{v}$ srede vyisokoobrazovannoy molodezhi: novyie vyizovyi staryih problem [Substance abuse situation in the environment of highly-educated youth: new chellenges of old problems]. Aktualnyie voprosyi psihicheskogo zdorovya, perspektivyi razvitiya psihiatricheskoy sluzhbyi / sost. V.A. Makasheva, D. Suvorova. Novosibirsk: Sibmedizdat, 2013: 17-22 (in Russian).

4. Vedyashkin V.N. Voprosyi reabilitatsii suitsidalnogo povedeniya $u$ detey i podrostkov Altayskogo kraya [Issues of realization of suicidal behavior in children and adolescents of the Altay Krai] Narusheniya povedeniya u detey, sovremennyie podhodyi k diagnostike i terapii: sbornik tezisov dokladov mezhregionalnoy nauchno-prakticheskoy konferentsii. Barnaul: Izd-vo «Arbat», 2015: 10-13 (in Russian).
5. Vedyashkin V.N., Sheremetyeva I.I. Izmeneniya klinikosotsialnyih harakteristik suitsidalnogo povedeniya podrostkovpatsientov narkologicheskogo statsionara za 10 let [Changes of clinical-social characteristics of suicidal behavior of adolescentspatients of a narcological hospital for 10 years]. XVI s'ezd psihiatrov Rossii. Vserossiyskaya nauchno-prakticheskaya konferentsiya s mezhdunarodnyim uchastiem «Psihiatriya na etapah reform: problemyi i perspektivyi [Elektronnyiy resurs] / pod obsch. red. N.G. Neznanova. SPb.: Alta Astra, 2015: 887 (in Russian).

6. Vedyashkin V.N., Sheremetyeva I.I. Organizatsiya profilaktiki i analiza suitsidalnogo povedeniya u detey i podrostkov Altayskogo kraya [Organization of prevention and analysis of suicidal behavior in children and adolescents of the Altay Krai]. Detskaya psihiatriya: sovremennyie voprosyi diagnostiki, terapii, profilaktiki i reabilitatsii: sb. materialov Vserossiyskoy nauchno-prakticheskoy konferentsii s mezhdunarodnyim uchastiem / pod red. N.G. Neznanova, I.V. Makarova. SPb., 2014: 23-24 (in Russian).

7. Vedyashkin V.N., Sheremetyeva I.I. Organizatsiya suitsidologicheskoy pomoschi podrostkam Altayskogo kraya [Organization of suicidological help for adolescents of the Altay Krai]. Sibirskiy vestnik psihiatrii $i$ narkologii - Siberian Herald of Psychiatry and Addiction Psychiatry. 2016; 3 (92): 75-80 (in Russian). 
8. Vedyashkin V.N., Sheremetyeva I.I. Osobennosti patomorfoza addiktsiy u podrostkov [Special characteristics of pathomorphism of addictions among adolescents]. Uralskiy meditsinskiy zhurnal Ural Medical Journal. 2014; 01 (115): 122-126 (in Russian).

9. Vedyashkin V.N., Sheremetyeva I.I. Patomorfoz suitsidalnogo povedeniya u podrostkov [Pathomorphism of adolescents' suicidal behavior]. Vestnik psihiatrii i psihologii Chuvashii - Bulletin of Psychiatry and Psychology of Chuvashia. 2015; 11 (3): 61-68 (in Russian).

10. Vostroknutov N.V., Shalimov V.F., Novikova G.R. Statsionarzameschayuschaya tehnologiya sotsialno-psihiatricheskoy pomoschi detyam [Hospital-substituting technoogy of socialpsychiatric care for children]: metodicheskie rekomendatsii. Moscow, 2010: 20 (in Russian).

11. Demdoumi N.Yu., Denisov Yu.P. Rasprostranenie «suitsidalnogo kontenta» $\mathrm{v}$ kiberprostranstve russkoyazyichnogo interneta kak problema multidistsiplinarnyih issledovaniy [Distribution of "The suicide content" in the cyberspace of the russian-speaking internet as the problem of multidisciplinary researches]. Suitsidologiya Suicidology. 2014; 5 (15): 47-54 (in Russian).

12. Dragunova T.V. Nekotoryie obschie voprosyi izucheniya lichnosti podrostka. [Some general issues of study of the personality of an adolescent]. Voprosyi izucheniya detey $s$ otkloneniyami $v$ povedenii: materialyi konferentsii. Moscow, 1968: 7-19 (in Russian).

13. Kakorina E.P., Kazakovtsev B.A., Golland V.D. Smertnost ot psihicheskih rasstroystv i smertnost pri psihicheskih rasstroystvah [Mortality from mental disorders and mortality for mental disorders]. Psihicheskoe zdorove - Mental Health. 2015; 3: 22-27 (in Russian).

14. Karavaeva T.A. Osobennosti izmeneniya strukturyi zabolevaemosti i klinicheskoy kartinyi nevroticheskih i nevrozopodobnyih rasstroystv za poslednie tri desyatiletiya [Features of change of the tructure of sickness rate and clinical picture of neurotic and neurosis-like disorders for last three decades]. Aktualnyie problemyi psihosomatiki v obschemeditsinskoy praktike: 10-ya nauchno-prakticheskaya konferentsiya / pod obsch. red. V.I. Mazurova. SPb., 2010: 75-79 (in Russian).

15. Karavaeva T.A. Patomorfoz nevroticheskih rasstroystv, ih psihoterapiya i pravovoe regulirovanie [Pathomorphosis of neurotic disorders, their psychotherapy and legal regulation]: avtoref. dis. ... doktora med. nauk. SPb., 2011: 57 (in Russian).

16. Kuzenkova N.N. Diagnostika i voenno-vrachebnaya ekspertiza psihicheskih rasstroystv u podrostkov [Diagnosis and militarymedical examination of mental disorders in adolescents]: metodicheskie rekomendatsii. Barnaul, 2003: 38 (in Russian).

17. Makushkin E.V. Kliniko-epidemiologicheskie harakteristiki psihicheskih rasstroystv u detey i podrostkov v RF [Clinicalepidemiological characteristics of mental disorders in children and adolescents in RF]. Aktualnyie voprosyi psihicheskogo zdorovya, perspektivyi razvitiya psihiatricheskoy sluzhbyi / sost. V.A. Makasheva, D. Suvorova. Novosibirsk: Sibmedizdat, 2013: 9-12 (in Russian).
18. Mozhginsky Yu.B. Psihicheskie bolezni u podrostkov: psihopatologiya, lechenie [Mental diseases in adolscents: psyhopathology, therapy]: klinicheskoe rukovodstvo. Moscow: Triadafarm, 2003: 215 (in Russian).

19. Na puti k prestupleniyu: deviantnoe povedenie podrostkov i riski vzrosleniya v sovremennoy Rossii (opyit sotsiologicheskogo analiza) [On the way to crime: deviant behavior of adolescents and risks of maturation in the modern Russia] / pod nauch. red. M.E. Pozdnyakovoy, T.A. Hagurova. Moscow; Krasnodar: Institut sotsiologii, 2012: 344 (in Russian).

20. Patomorfoz psihicheskih zabolevaniy $\mathrm{v}$ sudebno-psihiatricheskoy klinike [Pathmorphosis of mental diseases in forensic-psychiatric clinic]: sbornik nauch. trudov / pod red. G.V. Morozova. Moscow, 1985: 168 (in Russian).

21. Patomorfoz psihologicheskih harakteristik bolnyih s nevroticheskimi rasstroystvami za poslednie 30 let [Pathomorphosis of psychological characteristics of patients with neurotic disorders for last 30 years]. / B.D. Karvasarskiy, E.B. Mizinova, E.A. Kolotilschikova i dr. S-Petersburg., 2011: 28 (in Russian).

22. Soldatova G.V., Rasskazova E.I. Kak im pomoch? Rebenok v Internete: zapreschat, nablyudat ili ob'yasnyat? [How to help them? A child in the Inernet: forbide, observe or explain?] Deti $v$ informasionnom obschestve - Children in the Information Society. 2012; 0: 26-33 (in Russian).

23. Talalaeva G.V. Sotsialnaya demografiya [Social demography]. Uchebnoe posobie. Ekaterinburg, 2010: 173 (in Russian).

24. Tetenova E.Yu. Dinamika osnovnyih pokazateley upotrebleniya psihoaktivnyih veschestv u polzovateley russkoyazyichnogo segmenta Interneta (2008-2011 gg.) [Dynamics of Principal Drug Use Indicators among Russian-speaking Internet Users, 2008-2011]. Psihicheskoe zdorove - Mental Health. 2013; 5: 12-16 (in Russian).

25. Holmogorova A.B. Predislovie glavnogo redaktora [Editorial]. Konsultativnaya psihologiya i psihoterapiya - Counseling Psychology and Psychotherapy. 2016; 24 (3): 5-7 (in Russian).

26. Bertolote J.M.F., Fleischmann A. Suicidal behavior prevention: WHO perspectives on research. Am. J. Med. Genet. 2005; 133: 812.

27. Brauser D. Insufficient evidence to support universal suicide screening. Medscape medical news. 24.04.2013 URL: http://www.medscape.com/ viewarticle/803068.

28. Canavan N. Almost $20 \%$ of suicidal teens live in home with a gun. Medscape medical news. 08.05.2013 URL: http://www.medscape.com/ viewarticle/803856.

29. Chung R.H. Gender, ethnicity, and acculturation in intergenerational conflict of Asian American college students. Cultur Devers Ethnic Minor Psychol. 2001; 7 (4): 376-386.

Received September 17.2017 Accepted February 5.2018

Sheremetyeva Irina I., MD, Professor, Head of the Department of Psychiatry, Medical Psychology and Neurology with a course of additional vocational training, Altay State Medical University, Barnaul, Russian Federation.

Vedyashkin Victor N., candidate of medical sciences, Deputy Chief Medical Officer, Altay Regional Psychoneurological Clinic for Children, Barnaul, Russian Federation.

Sheremetyeva Irina I., sheremeteva-ira@ mail.ru 